\title{
Contact Dermatitis of the Vulva
}

\author{
Monica Corazza (D), Giulia Toni (D), Pierantonia Zedde*(D), Natale Schettini and Alessandro Borghi (D)
}

Department of Medical Sciences, Section of Dermatology and Infectious Diseases, University of Ferrara, Via A. Moro 8, 44121 Ferrara, Italy; czm@unife.it (M.C.); giuliatoni@hotmail.it (G.T.); natale.schettini@gmail.com (N.S.); alessandro.borghi@unife.it (A.B.)

* Correspondence: zddpnt@unife.it; Tel.: +39-0532-237303; Fax: +39-0532-238524

Citation: Corazza, M.; Toni, G.; Zedde, P.; Schettini, N.; Borghi, A. Contact Dermatitis of the Vulva. Allergies 2021, 1, 206-215. https:// doi.org/10.3390/allergies1040019

Received: 1 August 2021

Accepted: 21 October 2021

Published: 28 October 2021

Publisher's Note: MDPI stays neutral with regard to jurisdictional claims in published maps and institutional affiliations.

\begin{abstract}
The vulvar area is a common site of both irritative and allergic contact dermatitis due to the thin skin, easily traversable by irritant and allergic substances. The purpose of this review is to provide an overview of the most frequent allergens causing contact dermatitis in this particular site. A literature search was conducted via PubMed through May 2021. Relevant English language studies are included in this review. Fragrances, preservatives, botanical products, and topical medicaments were found to be the most commonly involved allergens. Contact dermatitis is a very common occurrence that should also be considered in patients with chronic vulvar or anogenital dermatitis who do not respond to appropriate treatments.
\end{abstract}

Keywords: contact dermatitis; vulvar dermatitis; allergic dermatitis

\section{Introduction}

The vulvar area is a common site of contact dermatitis due to the thin skin, easily traversable by irritant and allergic substances. The nonkeratinized vulvar vestibule is likely to be more permeable than the keratinized portions of the vulva and thus more susceptible to exogenous topical agents [1]. The vulva is an area of occlusion due to both its intrinsic anatomical structure and the frequent use of occlusive napkins or underwear, which increase penetration or absorption of both irritants and allergens. Furthermore, women at different ages, due to urine and feces as children and to vaginal mucosal atrophy and the increase in the vulvar $\mathrm{pH}$ in menopause, may have an altered barrier function and, in incontinent elderly subjects, the use of diapers may contribute to increased susceptibility to irritants and allergens.

\section{Purpose and Methods}

The purpose of this review is to focus on the contact dermatitis of the vulva with particular reference to the most frequent allergens responsible for vulvar allergic contact dermatitis.

All the studies dealing with this topic published in English-language literature were analysed in May 2021, with no date limitations. An electronic search was performed using the National Library of Medicine PubMed database. Papers not in English were excluded. The studies identified as relevant, including research articles, controlled studies, guidelines, reviews, case series, and case reports that raised important issues, were included in the present review.

The results of this analysis allowed us to provide a comprehensive picture of this issue, based on the available literature.

\section{Irritant Contact Dermatitis}

Irritant contact dermatitis (ICD) is the result of a direct damage to the skin by various chemical or physical stimuli. The initiating event is the disruption of the epidermal barrier (i.e., the stratum corneum), with consequent increased skin permeability. This results in 
an inflammatory cutaneous reaction, caused by proinflammatory mediators released from keratinocytes and by the activation of innate immunity [2,3]. Risk factors for vulvar ICD are multifactorial and include the type of irritant, the length of exposure, the presence of previous dermatoses, and the host's susceptibility. Women with an atopic diathesis (particularly atopic dermatitis) are more susceptible to ICD as a result of the impaired barrier function of their skin. Furthermore, vulvar skin shows an increased susceptibility to some irritants (maleic acid and benzalkonium chloride) [1]. ICD is more common than allergic contact dermatitis, but the exact prevalence is unknown. The most common vulvar irritants are reported in Table 1.

Table 1. List of the most common irritants responsible for vulvar ICD.

\begin{tabular}{ll}
\hline Vulvar Irritants & \\
\hline Strong Irritants & Weak Irritants \\
\hline Imiquimod & Friction/rubbing \\
\hline Trichloroacetic acid & $\begin{array}{l}\text { Urine/feces/vaginal } \\
\text { secretions/sweat/semen/saliva }\end{array}$ \\
\hline Podophyllin & Sanitary napkins \\
\hline 5-fluorouracil & Soaps/detergents \\
\hline & Antiseptic or scented wipes \\
\hline Sodium hypochlorite & Deodorants \\
\hline
\end{tabular}

Irritant contact dermatitis from strong irritants (caustics, topical medicaments) can have a rapid onset within minutes or hours of being exposed and presents with erythema, patches, papules, vesicles, bullae, and scaling. In chronic diseases (mostly due to weak cumulative allergens such as detergents or friction), lichenification and fissuring are more typical features. The main symptoms of ICD are burning, stinging, and, less frequently, itching or pain. In most cases the dermatitis is localized to the site of contact. In particular, when due to napkins ICD is located on the convex areas of the vulva, sparing the folds.

Avoiding use of the offending agents and providing patients education, together with the prescription of potent topical steroids to reduce inflammation, are crucial to the control of symptoms and signs.

\section{Allergic Contact Dermatitis}

Allergic contact dermatitis (ACD) is the consequence of a T-lymphocytes mediated immune reaction to small, molecular weight chemicals (haptens) that penetrate the skin and activate innate immunity and then the adaptive immunity [3]. During the sensitization phase, naive $T$ cells are activated in a process that involves Langerhans cells and dermal dendritic cells; in the elicitation phase, $\mathrm{T}$ cells migrate into the skin and induce skin damage through the release of proinflammatory cytokines and by killing haptenloaded keratinocytes.

The sensitization phase of ACD results in the expansion of skin-homing haptenspecific $T$ cells that, upon subsequent hapten challenge, migrate into the skin and induce the skin damage through the release of proinflammatory cytokines and by killing haptenloaded keratinocytes. Vulvar ACD may occur as a primary disorder or may complicate an underlying vulvar dermatosis. The risk of ACD increases in the case of pre-existing ICD and with the use of multiple topical treatments.

Vulvar ACD may develop as an acute eczema where the allergen was applied. In that case an itching vesicular or exudative eczema develops on previously healthy skin. However, the onset is often a complication of previous different cutaneous dermatoses (lichen sclerosus, psoriasis, atopic dermatitis, etc.) presenting as a local aggravation or exacerbation of symptoms and signs (Figure 1). The diagnosis may not be easy because of the confounding clinical aspects related to the preexisting dermatosis. In this case, 
history and the clinical aspect are very important in differentiating a lichen flare-up with an allergic dermatitis. The appearance of acute inflammatory lesions as erythema, edema, and vesiculation suggests contact sensitization. Furthermore, a poor response to an appropriate topical corticosteroid therapy could be indicative of contact sensitization to these molecules. The prolonged contact with the allergen can cause lichenification. (Figure 2).

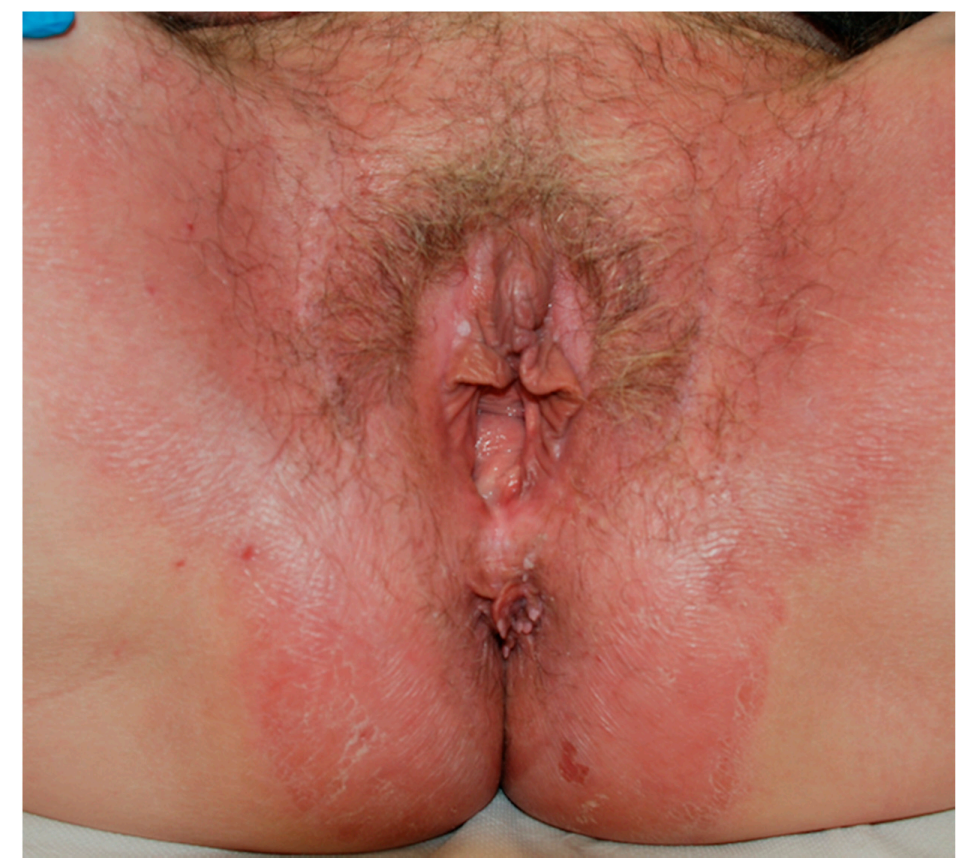

Figure 1. A case of psoriasis complicated by allergic contact dermatitis due to topical medications.

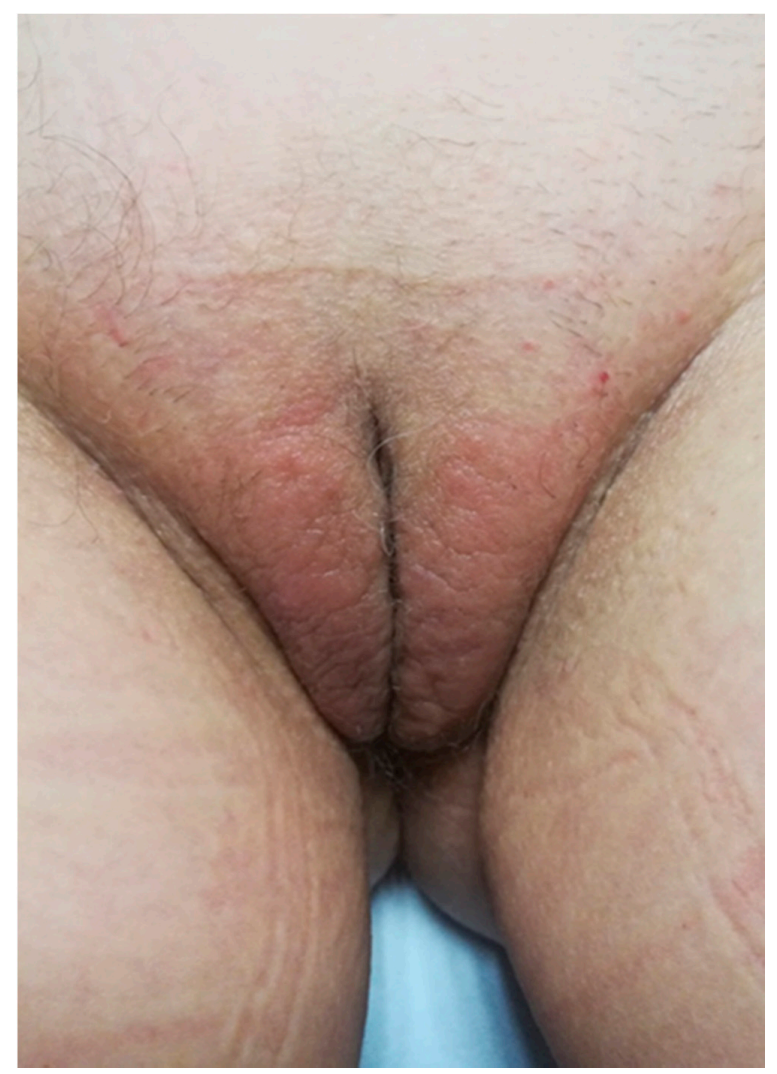

Figure 2. Lichenification following persistent allergic contact dermatitis. 
ACD can often severely affect quality of life for women who already suffer from a debilitating vulvar disease.

Sometimes the area of involvement spreads over the borders of the vulva not only due to the spread of inflammation but also because of the modality of contact with the allergens [4]. (Figure 3).

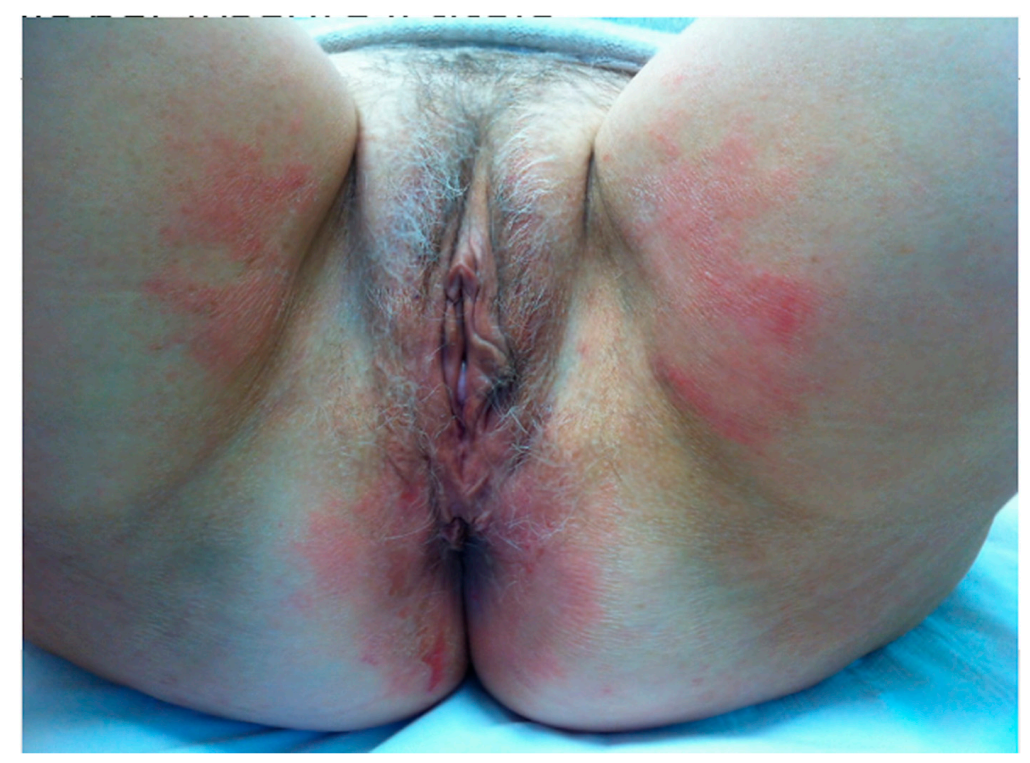

Figure 3. A case of allergic contact dermatitis in which the area of involvement spreads over the borders of the vulva.

Distant localizations may also develop due to inadvertent hand transfer or rubbing of the adjacent areas (e.g., thighs). The contamination of clothing or napkins may lead to persistent dermatitis. Furthermore, a rapid spread to distant sites (auto-eczematization) may also result from the absorption and diffusion of allergens inducing a sort of id-dermatitis. Clinically, vulvar irritation and allergic dermatitis can be difficult to distinguish, and diagnosis is made on the basis of history, clinical investigation, and patch testing.

A particular situation in vulvar ACD may be represented by the so-called "Connubial dermatitis", a dermatitis that occurs because of contact with substances transferred to the patients' skin by her partner. The diagnosis of connubial dermatitis should be considered in cases of probable allergic contact eczema when patch test results are apparently inconsistent with the patient's clinical history. In these situations, it may be necessary to extend medical investigation to the patient's partner as well, in order to clarify the source of allergic contacts when no obvious exposures can be found.

Vulvar ACD is frequently linked to direct contact with cosmetics and detergents or medicaments. Less frequently textiles or dyes are described. Sometimes unsuspected allergens such as nail varnish (ectopic contact dermatitis) can be the cause.

A review of the studies concerning vulvar ACD is reported in Table 2 [5-19].

It is not surprising that a high level of sensitization (39-78\%) is found testing patients affected by different vulvar disorders (vulvar symptoms, vulvar dermatoses, or anogenital symptoms). In selected conditions as well, like lichen simplex chronicus [20], similar percentages can be found. The reported incidence of clinically relevant patch test results for patients presenting with vulvar complaints are likewise high, ranging from $16 \%$ to $54 \%$ [5-19].

Fragrances, preservatives, and topical medicaments (especially corticosteroids, neomycin, and topical anesthetics) are the relevant allergens usually found. Although some authors consider nickel a relevant positivity for the disease, in the majority of cases it is considered a non-relevant allergen that simply reflects the high level of sensitization in the general population $[9,15,20]$. 
Table 2. Review of the studies concerning vulvar ACD.

\begin{tabular}{|c|c|c|c|c|c|c|}
\hline Authors & & Pathologies & $\mathbf{N}^{\circ}$ Patients & $\begin{array}{l}\% \\
\text { Positiveness }\end{array}$ & $\begin{array}{l}\% \\
\text { Relevant p.t. }\end{array}$ & Allergens \\
\hline Doherty et al. & 1990 & Vulvar itching & 50 & 78 & - & $\begin{array}{l}\text { nickel, fragrances, neomycin, } \\
\text { local anesthetics }\end{array}$ \\
\hline Marren et al. & 1992 & Vulvar dermatoses & 135 & 47 & 29 & $\begin{array}{l}\text { nickel, fragrances, preservatives, } \\
\text { ethylenediamine, topical } \\
\text { medicaments }\end{array}$ \\
\hline Brenan et al. & 1996 & $\begin{array}{l}\text { Chronic vulvar } \\
\text { symptoms }\end{array}$ & 700 & 42 & - & $\begin{array}{l}\text { nickel, fragrances, } \\
\text { ethylenediamine }\end{array}$ \\
\hline Goldsmith et al. & 1997 & $\begin{array}{l}\text { Anogenital } \\
\text { dermatoses }\end{array}$ & 201 & 39 & 28 & $\begin{array}{l}\text { antibiotics, local anesthetics, } \\
\text { fragrances, corticosteroids }\end{array}$ \\
\hline Lewis et al. & 1997 & Vulvar symptoms & 121 & 58.7 & 49 & $\begin{array}{l}\text { local anesthetics, fragrances, } \\
\text { neomycin }\end{array}$ \\
\hline Lucke et al. & 1998 & Vulvar dermatoses & 55 & 65 & - & $\begin{array}{l}\text { nickel, fragrances, medicaments, } \\
\text { dyes }\end{array}$ \\
\hline Bauer et al. & 2000 & $\begin{array}{l}\text { Anogenital } \\
\text { symptoms }\end{array}$ & 351 & 47 & 34.8 & $\begin{array}{l}\text { nickel, fragrances, local } \\
\text { anesthetics }\end{array}$ \\
\hline Crone et al. & 2000 & Vulvar dermatoses & 38 & 47 & 28 & $\begin{array}{l}\text { fragrances, preservatives, } \\
\text { medicaments }\end{array}$ \\
\hline Virgili et al. & 2003 & $\begin{array}{l}\text { Vulvar lichen } \\
\text { simplex chronicus }\end{array}$ & 61 & 47.5 & 26 & $\begin{array}{l}\text { nickel, preservatives, fragrances, } \\
\text { medicaments }\end{array}$ \\
\hline Nardelli et al. & 2004 & Vulvar symptoms & 92 & 38 & 16 & medicaments \\
\hline Utas et al. & 2008 & Vulvar itching & 50 & 52 & 16 & $\begin{array}{l}\text { preservatives, fragrances, } \\
\text { medicaments }\end{array}$ \\
\hline Haverhoek et al. & 2008 & Vulvar pruritus & 43 & 81.4 & 44 & $\begin{array}{l}\text { preservatives, fragrances, } \\
\text { medicaments }\end{array}$ \\
\hline Warshsoaw et al. & 2008 & $\begin{array}{l}\text { Anogenital } \\
\text { dermatoses }\end{array}$ & 570 & 44.1 & 27 & medicaments, corticosteroids \\
\hline Vermaat et al. & 2008 & $\begin{array}{l}\text { Anogenital } \\
\text { dermatoses }\end{array}$ & 53 & 66 & 20 & fragrances, spices \\
\hline O'Gorman et al. & 2013 & Vulvar itching & 90 & 69 & 39 & $\begin{array}{l}\text { preservatives, fragrances, } \\
\text { medicaments }\end{array}$ \\
\hline Al-Niaimi at al. & 2014 & Vulvar symptoms & 282 & 54 & 49 & nickel, fragrances, neomycin \\
\hline Trivedi et al. & 2018 & Vulvar itching & - & 64 & 54 & preservatives, fragrances \\
\hline
\end{tabular}

\subsection{Sensitizers}

\subsubsection{Fragrances}

Sensitizing fragrances have been identified in a large number of products, including cleansers, douches, toilet paper, personal hygiene sprays, sanitary or incontinence pads, and topical medications such as hemorrhoid creams. Fragrances are an important cause of vulvar ACD (Table 3) (Figure 4).

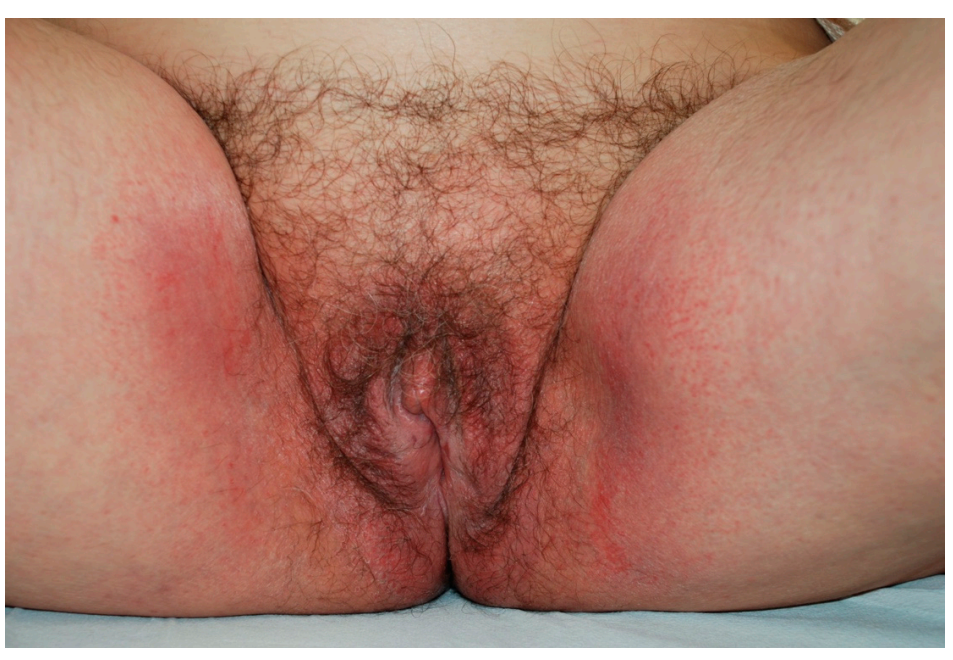

Figure 4. Allergic contact dermatitis due to fragrances contained in a soothing cream. 
Table 3. List of the most common fragrances and medicaments responsible for vulvar ACD.

\begin{tabular}{|c|c|c|}
\hline \multicolumn{3}{|c|}{ MEDICAMENTS } \\
\hline & ANTIBIOTICS & $\begin{array}{l}\text { Framycetin sulfate } \\
\text { Neomycin } \\
\text { Bacitracin } \\
\text { Streptomycin sulfate } \\
\text { Polymyxin }\end{array}$ \\
\hline & ANTIFUNGALS & $\begin{array}{l}\text { Terconazole } \\
\text { Clotrimazole } \\
\text { Miconazole } \\
\text { Nystatin }\end{array}$ \\
\hline & CORTICOSTEROIDS & $\begin{array}{l}\text { Hydrocortisone-17-butyrate } \\
\text { Clobetasol-17-propionate } \\
\text { Budesonide } 0.1 \% \\
\text { Tixocortol-21-pivalate }\end{array}$ \\
\hline & ANESTHETICS & $\begin{array}{l}\text { Esters (benzocaine, tetracaine, procaine) } \\
\text { Amides (dibucaine, lidocaine, cinchocaine) }\end{array}$ \\
\hline & BUFEXAMAE & \\
\hline & CROTAMITON & \\
\hline & ANTISEPTICS & $\begin{array}{l}\text { Chlorhexidine } \\
\text { Povidone-iodone } \\
\text { Cetrimide } \\
\text { Benzethonium chloride } \\
\text { Mercuric chloride } \\
\text { Gentian violet } \\
\text { Phenvlmercurium salts } \\
\text { Thiomerosal } \\
\text { Potassium dichromate }\end{array}$ \\
\hline FRAGRANCES & & $\begin{array}{l}\text { Balsam of Peru } \\
\text { Fragrances mix I and II } \\
\text { Perfume mix } \\
\text { Eugenol and Isoeugenol } \\
\text { Cinnamic aldehyde } \\
\text { Hydroxycitronellal } \\
\text { Hydroxyisohexyl 3-cyclohexene } \\
\text { carboldehyde }\end{array}$ \\
\hline
\end{tabular}

Most standard patch test series include fragrance mix I, Myroxylon pereirae (balsam of Peru), and fragrance mix II. Fragrance mix I is composed of amyl cinnamal, cinnamyl alcohol, cinnamal, eugenol, geraniol, hydroxycitronellal, isoeugenol, oak moss absolute, and sorbitan sesquioleate. Fragrance mix II is composed of lyral, citral, citronellol, farnesol, hexyl cinnamic aldehyde, and coumarin. Balsam of Peru is a naturally occurring compound derived from the South American tree, Myroxylon pereirae. It includes benzyl acetate, benzyl alcohol, cinnamic acid, cinnamic alcohol, cinnamic aldehyde, eugenol, and isoeugenol [21].

Sensitivity to fragrance mixes I and II, and M. pereirae has been reported in numerous studies $[5,8,11,14,17]$.

A retrospective, cross-sectional study including 347 patients (both male and female) with anogenital diseases found fragrances to be the most frequent allergens [18]; M. pereirae, fragrance mix I, and cinnamal were positive, respectively, in $26.7 \%, 20.6 \%$, and $5.5 \%$ of patients with anogenital dermatitis.

Many studies found a significant number of patients with genital ACD to be allergic to fragrance mix I or balsam of Peru [11,14,17,22-24].

Together, these two fragrance screening agents were found to be clinically relevant in up to $20 \%$ of patients with genital ACD [11]. In other studies, fragrance sensitization was less frequently detected but almost always clinically relevant [15]. 


\subsubsection{Preservatives}

Preservatives are additive substances with biostatic or biocidal power; they are added in topical products, especially emulsions and solutions, to prevent microbial proliferation. Preservatives are often used in synergistic mixtures; the most used are the esters of paraoxybenzoic acid (effective against fungi and molds) and formaldehyde releasers (more effective against bacteria).

Numerous studies confirm that preservatives are a frequent cause of vulvar $\operatorname{ACD}[6,14,15,18,21]$. In a retrospective study, the preservatives most associated with anogenital ACD were quarternium-15 (13.7\%), paraben mix $12 \%(8.2 \%)$, methylchloroisothiazolinone/methylisothiazolinone (MCI/MI) (6.9\%), ethylenediamine dihydrochloride (5.7\%), and 2-bromo-2-nitropropane-1,3-diol (5.5\%) [18].

The role of the ethylenediamine as an allergen is confirmed by a study in which its positivity reached $8 \%[6]$.

Benzoic acid is reported as a frequent cause of iatrogenic ACD (particularly associated with antifungal medication) in the genital area [25]. Isothiazolinones seem to play a predominant role in the etiology of genital ACD [26-29]. They are found in intimate cleansers, cleansing wipes, and detergents [30,31]; in Europe their use has been restricted because of the high rates of sensitization.

A recent study on the association between vulvar sensitization to MI and vulvodynia showed that repeated MI exposures can provoke allergy-driven genital pain [32].

Preservatives must be considered as a possible cause of vulvar ACD as they are always present in topical products; it is often very difficult to trace the preservative involved.

\subsubsection{Medicaments}

A variety of topical medications are used, often empirically or for self-prescription, in the management of vulvar symptoms. Corticosteroid creams/ointments, anti-itch creams, antibiotics, antifungal creams, and hormonal creams have been implicated in vulvar ACD.

In 2008 the North American Contact Dermatitis group determined that the most clinically relevant medicaments in anogenital ACD were local anesthetics, antibiotics, and corticosteroids. Clinically relevant reactions to anesthetics among patients with anogenital ACD were high, with $12.5 \%$ of the patients reacting to benzocaine and $13.5 \%$ to dibucaine [18]. The "caine" anesthetics are widely recognized causes of topical medication-induced genital ACD [10]. Esther anesthetics (benzocaine, procaine, and tetracaine) are known allergens and cross-react with sulfa drugs, para-aminobenzoic acid, paraphenylenediamine, and thiazide diuretics $[14,33]$.

In patients with vulvar disease, a history of sulfa allergy or hair dye allergy can provide diagnostic clues to the culprit allergen [14]. Unfortunately, benzocaine is frequently present in over-the-counter topical anti-itch preparations, such as Vagisil, or antihemorrhoidal creams $[19,34]$. Amide anesthetics (bupivacaine, lidocaine, dibucaine, mepivacaine, and prilocaine) have also been reported but they seem to be less potent and less common sensitizers [33].

As reported by several studies, neomycin is the most common allergen among topical antibiotic preparations. Drugs that cross-react with neomycin include framycetin, streptomycin, bacitracin, kanamycin, gentamicin, and tobramycin $[4,5,8]$. In a study by Al-Niaimi et al., topical antibiotics (specifically neomycin and framycetin), along with anesthetics, were the most common cause of sensitization among the $49 \%$ of clinically relevant patch test results [15]. In a retrospective analysis, $9.7 \%$ of patients with anogenital ACD had clinically relevant reactions to neomycin and 5.5\% reacted to bacitracin [18].

Topical corticosteroids may be sensitizers, due to the steroid molecule itself or its vehicle components. Genital contact sensitization rates for topical corticosteroids range from $1.1 \%$ to $3.3 \%$ [17]. Positive patch tests to clobetasol and tixocortol pivalate were found in patients using topical steroids for pre-existing dermatoses such as lichen sclerosus or vulvar eczema [5]. 
Corticosteroids were one of the most common relevant allergens in patients with anogenital ACD; reactions to hydrocortisone-17-butyrate (13.5\%), clobetasol-17-propionate $(10.8 \%)$, budesonide $0.1 \%(9.7 \%)$, and tixocortol-21-pivalate $(6.9 \%)$ were noted. Sensitization to topical corticosteroids should be considered in patients with vulvar dermatoses that respond poorly to the appropriate corticosteroid therapy.

Antimycotics can cause ACD as well. Imidazoles are the most frequently prescribed topical antifungal drugs. ACD caused by them is regarded as rare considering their high prescription rates [35]. Among the imidazoles, miconazole is the most frequent contact sensitizer [36]. A study showed that $1.8 \%$ of patients with positive patch test results were sensitized to clotrimazole [10]. Clotrimazole is a synthetic, broad-spectrum, phenethyl imidazole, and a cross-reaction between clotrimazole and miconazole was observed in some case reports $[35,36]$.

Terconazole was shown to affect over twice the number of patients as other antifungals, with up to $7 \%$ sensitization [14].

Rare cases of sensitization to nystatin have also been reported [37].

\subsubsection{Botanical Products}

Botanical products are very popular especially due to the belief that they are safer than synthetic products $[38,39]$. These products are contained in creams, vaginal suppositories, and plugs as active principle/raw material, additives, or excipients. They are known allergens [40-43]. Many cases of ACD due to the use of botanical extracts are described in the literature concerning the vulvar area $[13,44,45]$.

In an Italian study, about $60 \%$ of patients with chronic vulvar complaints reported use of botanical products, among which $16.7 \%$ reported adverse effects to them [39].

The most commonly used medicinal plants were chamomile, Aloe vera, and Calendula officinalis.

It must be emphasized that a considerable rate of patients who complained of cutaneous side effects due to natural products was not sensitized to the natural active principle. Among the patients referring cutaneous side reactions to botanical products, only $57.1 \%$ showed at least one positive reaction, and in testing the patients with integrative botanical series only $28.7 \%$ relevant positivities were found. These results also suggest that the botanical integrative series does not improve diagnostic accuracy; they should be tested only in particular cases of strong clinical-anamnestic suspicion.

Sometimes fragrances and preservatives may be the true responsible allergens in cases of suspected ACD attributable to herbal components.

A peculiarity of botanical extracts is the possibility of causing allergic sensitization after excretion via urine or feces after ingestion [13].

\section{Conclusions}

In patients with chronic vulvar or anogenital dermatitis, the possibility of an ACD should be taken into consideration early in the course of the disease, especially in patients who do not respond to appropriate treatments. Prompt and accurate diagnosis of vulvar ACD in patients with a pre-existing vulvar disease is important because their symptoms will not improve until this diagnosis is made and appropriately managed.

To take a detailed history in patients with vulvar dermatitis and to discover relevant allergens is crucial. We suggest initially performing patch tests with the European baseline series and then with additional series with fragrances, preservatives, medicaments, and botanical extracts. We also strongly recommend testing with the patients' own products as well [25].

Funding: This research received no external funding.

Conflicts of Interest: The authors declare no conflict of interest. 


\section{References}

1. Farage, M.A. Vulvar susceptibility to contact irritants and allergens: A review. Arch. Gynecol. Obstet. 2005, 272, 167-172. [CrossRef] [PubMed]

2. Bains, S.N.; Nash, P. Irritant Contact Dermatitis. Clin. Rev. Allergy Immunol. 2019, 56, 99-109. [CrossRef]

3. Nosbaum, A.; Vocanson, M.; Rozieres, A.; Hennino, A.; Nicolas, J.F. Allergic and irritant contact dermatitis. Eur. J. Dermatol. EJD 2009, 19, 325-332. [CrossRef]

4. Davis, M.D.P. Unusual patterns in contact dermatitis: Medicaments. Dermatol. Clin. 2009, 27, 289-297. [CrossRef] [PubMed]

5. Marren, P.; Wojnarowska, F.; Powell, S. Allergic contact dermatitis and vulvar dermatoses. Br. J. Dermatol. 1992, 126, 52-56. [CrossRef]

6. Brenan, J.A.; Dennerstein, G.J.; Sfameni, S.F.; Drinkwater, P.; Marin, G.; Scurry, J.P. Evaluation of patch testing in patients with chronic vulvar symptoms. Australas. J. Dermatol. 1996, 37, 40-43. [CrossRef] [PubMed]

7. Goldsmith, P.C.; Rycroft, R.J.G.; White, I.R.; Ridley, C.M.; Neill, S.M.; McFadden, J.P. Contact sensitivity in women with anogenital dermatoses. Contact Dermat. 1997, 36, 174-175. [CrossRef]

8. Lewis, F.M.; Harrington, C.I.; Gawkrodger, D.J. Contact sensitivity in pruritus vulvae: A common and manageable problem. Contact Dermat. 1994, 31, 264-265. [CrossRef]

9. Lucke, T.W.; Fleming, C.J.; McHenry, P.; Lever, R. Patch testing in vulval dermatoses: How relevant is nickel? Contact Dermat. 1998, 38, 111-112. [CrossRef] [PubMed]

10. Bauer, A.; Geier, J.; Elsner, P. Allergic contact dermatitis in patients with anogenital complaints. J. Reprod. Med. 2000, 45, 649-654.

11. Crone, A.M.; Stewart, E.; Wojnarowska, F.; Powell, S.M. Aetiological factors in vulvar dermatitis. J. Eur. Acad. Dermatol. Venereol. JEADV 2000, 14, 181-186. [CrossRef] [PubMed]

12. Utaş, S.; Ferahbaş, A.; Yildiz, S. Patients with vulval pruritus: Patch test results. Contact Dermat. 2008, 58, 296-298. [CrossRef]

13. Vermaat, H.; Van Meurs, T.; Rustemeyer, T.; Bruynzeel, D.P.; Kirtschig, G. Vulval allergic contact dermatitis due to peppermint oil in herbal tea. Contact Dermat. 2008, 58, 364-365. [CrossRef] [PubMed]

14. O'Gorman, S.M.; Torgerson, R.R. Allergic contact dermatitis of the vulva. Dermat. Contact Atopic Occup. Drug 2013, $24,64-72$. [CrossRef] [PubMed]

15. Al-Niaimi, F.; Felton, S.; Williams, J. Patch testing for vulval symptoms: Our experience with 282 patients. Clin. Exp. Dermatol. 2014, 39, 439-442. [CrossRef]

16. Trivedi, M.K.; Woodruff, C.M.; Kornik, R.; Botto, N. Patch Testing in Vulvar Allergic Contact Dermatitis. Dermat. Contact Atopic Occup. Drug 2018, 29, 95-96. [CrossRef] [PubMed]

17. Nardelli, A.; Degreef, H.; Goossens, A. Contact allergic reactions of the vulva: A 14-year review. Dermat. Contact Atopic Occup. Drug 2004, 15, 131-136. [CrossRef] [PubMed]

18. Warshaw, E.M.; Furda, L.M.; Maibach, H.I.; Rietschel, R.L.; Fowler, J.F., Jr.; Belsito, D.V.; Zug, K.A.; DeLeo, V.A.; Marks, J.G., Jr.; Toby Mathias, C.G.; et al. Anogenital dermatitis in patients referred for patch testing: Retrospective analysis of cross-sectional data from the North American Contact Dermatitis Group, 1994-2004. Arch. Dermatol. 2008, 144, 749-755. [CrossRef]

19. Haverhoek, E.; Reid, C.; Gordon, L.; Marshman, G.; Wood, J.; Selva-Nayagam, P. Prospective study of patch testing in patients with vulval pruritus. Australas. J. Dermatol. 2008, 49, 80-85. [CrossRef]

20. Virgili, A.; Bacilieri, S.; Corazza, M. Evaluation of contact sensitization in vulvar lichen simplex chronicus. A proposal for a battery of selected allergens. J. Reprod. Med. 2003, 48, 33-36.

21. Woodruff, C.M.; Trivedi, M.K.; Botto, N.; Kornik, R. Allergic Contact Dermatitis of the Vulva. Dermat. Contact Atopic Occup. Drug 2018, 29, 233-243. [CrossRef] [PubMed]

22. Yale, K.; Awosika, O.; Pardo, M.R.; Ehrlich, A. Genital Allergic Contact Dermatitis. Dermat. Contact Atopic Occup. Drug 2018, 29, 112-119. [CrossRef] [PubMed]

23. Bhate, K.; Landeck, L.; Gonzalez, E.; Neumann, K.; Schalock, P. Genital contact dermatitis: A retrospective analysis. Dermat. Contact Atopic Occup. Drug 2010, 21, 317-320. [CrossRef]

24. Ljubojević, S.; Lipozencić, J.; Celić, D.; Turcić, P. Genital contact allergy. Acta Dermatovenerol. Croat. ADC 2009, 17, 285-288. [PubMed]

25. Gilissen, L.; Schollaert, I.; Huygens, S.; Goossens, A. Iatrogenic allergic contact dermatitis in the (peri)anal and genital area. Contact Dermat. 2021, 84, 431-438. [CrossRef] [PubMed]

26. Timmermans, A.; De Hertog, S.; Gladys, K.; Vanacker, H.; Goossens, A. 'Dermatologically tested' baby toilet tissues: A cause of allergic contact dermatitis in adults. Contact Dermat. 2007, 57, 97-99. [CrossRef] [PubMed]

27. Tosti, A.; Voudouris, S.; Pazzaglia, M. Contact sensitization to 5-chloro-2-methyl-4-isothiazolin-3-one and 2-methyl-4-isothiazolin3-one in children. Contact Dermat. 2003, 49, 215-216. [CrossRef] [PubMed]

28. Fields, K.S.; Nelson, T.; Powell, U. Contact dermatitis caused by baby wipes. J. Am. Acad. Dermatol. 2006, 54, S230-S232. [CrossRef]

29. Gardner, K.H.; Davis, M.D.P.; Richardson, D.M.; Pittelkow, M.R. The hazards of moist toilet paper: Allergy to the preservative methylchloroisothiazolinone/methylisothiazolinone. Arch. Dermatol. 2010, 146, 886-890. [CrossRef]

30. Foote, C.A.; Brady, S.P.; Brady, K.L.; Clark, N.S.; Mercurio, M.G. Vulvar dermatitis from allergy to moist flushable wipes. J. Low. Genit. Tract Dis. 2014, 18, E16-E18. [CrossRef] [PubMed]

31. Monroe, H.R.; Hu, J.C.; Chiu, M.W. Methylchloroisothiazolinone / methylisothiazolinone and moist wipe dermatitis. Dermatol. Online J. 2010, 16, 14. [PubMed] 
32. Arriaga-Gomez, E.; Arriaga-Gomez, E.; Kline, J.; Emanuel, E.; Neamonitaki, N.; Yangdon, T.; Zacheis, H.; Pasha, D.; Lim, J.; Bush, S.; et al. Repeated Vaginal Exposures to the Common Cosmetic and Household Preservative Methylisothiazolinone Induce Persistent, Mast Cell-Dependent Genital Pain in ND4 Mice. Int. J. Mol. Sci. 2019, 20, 5361. [CrossRef]

33. Schlosser, B.J. Contact dermatitis of the vulva. Dermatol. Clin. 2010, 28, 697-706. [CrossRef]

34. Margesson, L.J. Contact dermatitis of the vulva. Dermatol. Ther. 2004, 17, 20-27. [CrossRef]

35. Corazza, M.; Scuderi, V.; Toni, G.; Forconi, R.; Zedde, P.; Borghi, A. Severe vulvovaginal allergic contact dermatitis due to clotrimazole contained in multiple topical products. Contact Dermat. 2020, 82, 57-59. [CrossRef] [PubMed]

36. Mahajan, V.; Mehta, K.; Chauhan, P.; Abhinav, C. Allergic contact dermatitis due to clotrimazole with cross-reaction to miconazole. Indian J. Dermatol. Venereol. Leprol. 2015, 81, 80-82. [CrossRef]

37. Wasilewski, C. Allergic contact dermatitis from nystatin. Arch. Dermatol. 1971, 104, 437. [CrossRef]

38. Corazza, M.; Borghi, A.; Lauriola, M.M.; Virgili, A. Use of topical herbal remedies and cosmetics: A questionnaire-based investigation in dermatology out-patients. J. Eur. Acad. Dermatol. Venereol. JEADV 2009, 23, 1298-1303. [CrossRef] [PubMed]

39. Corazza, M.; Virgili, A.; Toni, G.; Minghetti, S.; Tiengo, S.; Borghi, A. Level of use and safety of botanical products for itching vulvar dermatoses. Are patch tests useful? Contact Dermat. 2016, 74, 289-294. [CrossRef] [PubMed]

40. Mortimer, S.; Reeder, M. Botanicals in Dermatology: Essential Oils, Botanical Allergens, and Current Regulatory Practices. Dermat. Contact Atopic Occup. Drug 2016, 27, 317-324. [CrossRef]

41. Kiken, D.A.; Cohen, D.E. Contact dermatitis to botanical extracts. Am. J. Contact Dermat. Off. J. Am. Contact Dermat. Soc. 2002, 13, 148-152.

42. de Groot, A.C.; Schmidt, E. Essential Oils, Part IV: Contact Allergy. Dermat. Contact Atopic Occup. Drug 2016, $27,170-175$. [CrossRef] [PubMed]

43. Simpson, E.L.; Law, S.V.; Storrs, F.J. Prevalence of botanical extract allergy in patients with contact dermatitis. Dermat. Contact Atopic Occup. Drug 2004, 15, 67-72. [CrossRef] [PubMed]

44. Romita, P.; Foti, C.; Gullo, G.; Ambrogio, F.; DiMauro, D.; Calogiuri, G. Genital allergic contact dermatitis in response to contact to thyme in a sanitary pad. Contact Dermat. 2020, 82, 169-170. [CrossRef]

45. Corazza, M.; Borghi, A.; Gallo, R.; Schena, D.; Pigatto, P.; Lauriola, M.M.; Guarneri, F.; Stingeni, L.; Vincenzi, C.; Foti, C.; et al. Topical botanically derived products: Use, skin reactions, and usefulness of patch tests. A multicentre Italian study. Contact Dermat. 2014, 70, 90-97. [CrossRef] [PubMed] 